\title{
La transición al feudalismo en el territorio astorgano en el siglo $\mathrm{X}$
}

\author{
Jesús Ma Laguardia Álvarez
}

La larga transición entre el sistema esclavista y el feudal quedó cortada en la Península Ibérica con la llegada de los musulmanes y la implantación de una nueva organización basada en las relaciones tribales que caracterizaban a las sociedades árabe, siria y bereber, entre otras. En las zonas peninsulares que definitivamente quedaron fuera del control - por lo menos directo- de este nuevo poder, la evolución fue distinta por mor de las diversas circunstancias de cada uno de estos espacios. Así, los más cercanos a los Pirineos recibieron la influencia, y la presión, de los francos. En la actual Cataluña éstos consolidaron su poder, mientras que en la zona navarra y aragonesa los nativos se sacudieron su influencia durante el siglo Ix. En cambio, en las tierras sitas al norte del río Duero las influencias foráneas fueron menores, limitándose a fugitivos hispanovisigodos -las menores-y mozárabes - las mayores- que se instalaron entre galaicos, astures, cántabros y vascones, a pesar de que la caracterización cultural de los recién llegados era bastante distinta de la que tenían estos últimos.

La interpretación de esta etapa de nuestra historia ha sido compleja. La visión más institucional, encabezada por Claudio Sánchez Albornoz, era una concepción jurídico-política que negaba la existencia de feudalismo en Castilla. Una de sus claves era la distinción entre régimen feudal y régimen señorial ${ }^{1}$.

La aparición, a mediados de la década de los setenta, de las obras de A. Barbero y $M$. Vigil han supuesto un auténtico giro en el estudio del

Sus obras más representantivas son En torno a los origenes del feudalismo, 3 vols., Mendoza, 1942 y España, un enigma histórico, 2 vols., Buenos Aires, 1956. Entre los que han seguido su línea interpretativa destaca L. GarCí DE VALDEAVELLANo, El feudalismo hispánico y otros estudios de historia medieval, Barcelona, 1981. 
feudalismo castellano ${ }^{2}$. Desde ese momento el feudalismo dejaba de ser visto desde un punto de vista institucional. La sociedad medieval era interpretada globalmente desde presupuestos que partían del materialismo histórico. La ampliación de las posibilidades metodológicas ha posibilitado nuevos modelos para explicar lo sucedido entre los siglos III y xII en tierras españolas ${ }^{3}$.

Centrados en la zona habitada por los pueblos caniábricos y siguiendo las tesis abiertas por los trabajos de A. Barbero y M. Vigil, la transición hacia formas feudales se produce a través de la disolución de dos sistemas de producción previos: el esclavismo y las sociedades gentilicias. Estos pueblos habrían quedado al margen del mundo romano y visigodo, aunque sin dejar de evolucionar desde sus posiciones gentilicias hacia estructuras típicas de las sociedades antes citadas. Así, para el siglo VIII cántabros y astures son capaces de unirse - personalizados en las familias de Pelayo y Alfonso 1-, superar su marco de actividad y lanzarse al control de otros territorios: los de los galaicos y vascones, primero, y los del valle del Duero, ya durante la segunda mitad del siglo ix. Precediendo a esta acción dirigida por la monarquía astur está, sin duda, el asentamiento en los valles durienses de grupos de pioneros que pudieron encontrarse con grupos humanos que se habían mantenido en el valle.

Dejando a un lado la cuestión de la mayor o menor despoblación del valle del Duero, es la repoblación dirigida por la monarquía astur la causante de la estructura política, social y económica que se implanta en el valle del Duero desde mediados del siglo Ix. Evidentemente, este sistema está más cercano al feudalismo que al esclavismo y al gentilicio. Así, por una parte se sitúa el grupo minoritario rector formado por el rey y un grupo de aristócratas laicos y eclesiásticos; por otra, la masa de campesinos que en muchos casos es propietaria de las tierras que trabaja.

Hasta aquí todavía coinciden, más o menos, las dos principales corrientes historiográficas. La institucionalista, encabezada por C. Sánchez Albornoz, señala que es esta masa de campesinos la que impide el

2 Sobre los origenes sociales de la Reconquista, Barcelona, 1974, y La formación del feudalismo en la Peninsula lbérica, Barcelona, 1978.

3 Entre los trabajos más destacados hay que citar: J. M. Minguez, «Ruptura social e implantación del feudalismo en el noroeste peninsular (Siglos vill-x)", Studia Historica, Historia Medieval, III, 1985, y los contenidos en En torno al feudalismo hispánico, Ávila, 1989, que incluye intervenciones de A. Barbero, J. M. Mínguez, C. Estepa, etc. 
desarrollo del feudalismo en tierras del valle del Duero, ya que la monarquía no es juguete de la ambiciosa aristocracia gracias a la cantidad de tierras que aporta la repoblación y permite controlar a aquélla. Por su parte, el campesinado se ve libre de la presión señorial que está asolando parte de Europa al ser propietario de sus explotaciones.

Los que lo han estudiado desde una perspectiva global apuntan que desde un primer momento el campesinado recibe la presión del grupo aristocrático. Ésta aumenta cuando la monarquía cede parte de su poder a la aristocracia a raíz de la lucha que se sucede durante la segunda mitad del siglo $x$. Con ello se consuma la transición hacia formas y estructuras feudales.

Metodológicamente hablando en este artículo se opta por realizar un análisis global de la sociedad teniendo en cuenta todos sus aspectos, sin centrarse sólo en los político-institucionales. El objetivo principal es señalar las manifestaciones que en una determinada zona del reino asturleonés están reflejando, durante el siglo $\mathrm{x}$, el triunfo del feudalismo.

El territorio astorgano es una típica circunscripción medieval compuesta por diversas comarcas que gravitan en torno a un centro de poder. En este caso se trata de Astorga, residencia del obispo de la diócesis del mismo nombre, que después de León es lo más cercano a una ciudad, y cabeza de un condado de difícil seguimiento, ya que el cargo de conde no aparece vinculado a ningún linaje en particular. En definitiva, es la figura del obispo el eje sobre el que se articulan las relaciones en dicho territorio y con la capital León, que aglutina, como parece normal en todos los centros de poder, a un importante círculo de eclesiásticos, y de laicos.

Esta posición de la jerarquía eclesiástica, común a cada una de las diócesis, forma parte de la estructura de poder creada a raíz de la expansión de la monarquía astur por la vertiente norte del valle del Duero. Para ello ésta ha tenido que ceder un importante patrimonio a la jerarquía eclesiástica, y a los magnates laicos que hacen una función parecida a la hora de administrar los diferentes territorios del cada vez más extenso reino. La entrega de tierras no ha supuesto para la monarquía una gran pérdida gracias a las posibilidades de la repoblación. La situación se plantea diferente después del reinado de Ramiro II cuando el avance repoblador se estabiliza en el río Duero. No parece que sea una simple coincidencia el parón repoblador y las rebeliones protagonizadas por la aristocracia en la segunda mitad del siglo $x$.

La procedencia eclesiástica de la mayor parte de la documentación permite seguir con cierto rigor el proceso de patrimonialización de muchas 
instituciones religiosas ${ }^{4}$. En cambio la aristocracia laica ha dejado una menor huella documental. Lo cual no quiere decir que con ellos la monarquía hubiese actuado de manera distinta. Por lo que al territorio astorgano concierne, las donaciones reales a la aristocracia laica aumentan considerablemente en el último tercio del siglo x como consecuencia de la crítica situación de la monarquía leonesa. Según la historiografía tradicional e institucionalista es debido al poder del califato cordobés; según las tendencias que tienen una visión global de los acontecimientos es la presión que ejerce la aristocracia laica sobre la monarquía, producto de las transformaciones que están aconteciendo en la sociedad en su transición hacia el feudalismo ${ }^{5}$. Paralelamente el campesinado también recibe la presión de la aristocracia. De esta manera, se consolida a lo largo del siglo $x$ una estructura política, social y económica que apunta hacia el feudalismo: la soberania monárquica comienza a fragmentarse; la aristocracia asume parcelas de poder reservadas al rey, creando una red de vínculos personales con vasallos y colonos en sus dominios; y el campesinado entra en un proceso de dependización. Gracias al apoyo monárquico y por propia iniciativa la aristocracia intenta acumular la mayor cantidad de poder político, económico y social sobre los campesinos, agrupados en comunidades de aldea, en las que la evolución interna se encamina también hacia la jerarquización y la desigualdad ${ }^{6}$. A ello van a ayudar, sin duda, las presiones de agentes externos. El resultado es la entrada en dependencia de la nayoría de las comunidades de aldea, aunque durante el siglo $x$ este proceso no haya hecho más que empezar. Lo cual dificulta su análisis al no estar muy claras instituciones y situaciones que a lo largo de los siglos XI y XII se van clarificando, ya que la articulación entre la aristocracia de señores feudales y los campesinos de las aldeas se hace lenta e individualizada o colectivamente a través de donaciones reales, compras, préstamos, profiliaciones, vinculaciones personales, etc.

Para analizar este proceso de feudalización, que a su primera fase $C$. Estepa ha llamado de formación de la propiedad dominical ${ }^{7}$, es necesario hablar primero de las donaciones reales. Una cuestión complicada de por

" En lo que concierne a la documentacióni relativa a la catedral astorgana no ha habido mucha suerte ya que prácticamente sólo se conservan extractos de la mayoría de sus documentos en el manuscrito 4357 de la Biblioteca Nacional.

5 J. M. Minguez, "Las sociedades feudales. Antecedentes, formación y expansión (siglos vı al XIII)", en Historia de España II, 1994, pág. 156.

6 Id., pp. 137-138.

7 C. ESTEPA, «Formación y consolidación del feudalismo en Castilla y León», en En torno al feudalismo hispánico, 1 Congreso de Estudios Históricos (1987), Ávila, 1989, pp. 157-256. Concretamente en la página 162 define los tres tipos de propiedad: dominical, señorial y jurisdiccional. La 
sí ya que no hay, en principio, demasiada uniformidad. Así, se puede donar la propiedad de una explotación o de una aldea, la jurisdicción sobre una aldea e incluso los bienes de explotación colectiva de una aldea, además de otras posibilidades que se nos escapan. Sin duda esta diversidad es producto de las ya citadas transformaciones que vive la sociedad asturleonesa en su transición al feudalismo.

Como no son muchas las donaciones hechas por la monarquía astur que se han conservado en relación al territorio astorgano se puede hacer referencia a todas ellas. Así, el 2 de febrero del año 895, Alfonso III entrega a la iglesia de San Martín de Parada y Cebraria - despoblado cercano a Astorga- una villa en dicho lugar 8 ; el 8 de enero del año 918, Ordoño II dona al monasterio de Santiago de Valdevimbre un busto lindante con Bercianos del Páramo 9; el 1 de agosto del año 937, Ramiro Il dona al monasterio de San Andrés de Montes la villa llamada Orniola - despoblado cercano a Molinaferrera- ${ }^{10}$; el 11 de abril del año 940, Ramiro II dona al monasterio de Santiago de Peñalba la iglesia de San Martín de Parada y Cebraria ${ }^{11}$; el 15 de mayo del año 951, Ordoño III dona al monasterio de Sahagún las villas llamadas Matilla y Magretes — despoblados cercanos al río Esla- ${ }^{12}$; el 4 de mayo del año 958, Ordoño Il dona a su tía doña Paterna un busto cercano a Alcoba de la Ribera ${ }^{13}$; el 10 de marzo del año 989, Vermudo Il dona a Froila Vimarédiz, «armiger regis», una villa en Antoñán del Valle ${ }^{14}$; el 25 de diciembre de ese mismo año dona al conde Munio Fernández la villa llamada Toral de los Guzmanes ${ }^{15}$; el 29 de julio del año 991 dona a Savarigo, obispo de León, una villa en la vega del río Duerna ${ }^{16}$; el 2 de junio del año 994 dona a Fernando Núñez las villas

primera se caracteriza por el poder económico sobre la tierra y los hombres, tiene sus origenes en la repoblación; la segunda supone cierto poder jurisdiccional basado en la dependencia vasallática de un señor, principalmente desde el siglo xil; la tercera es una expresión más concreta y desarrollada de la anterior.

B B.N., ms. 4357, fol. $17 \mathrm{~V}, \mathrm{n}^{\circ} 132$.

9 E. SÁEZ, Colección documental del archivo de la Catedral de León (775-1230), 1, (775-952), León, 1987, pp. 75-76, n 45. Más bien es la confirmación de una concesión anterior, ya que la acción se remonta al reinado de Alfonso III.

10 A. Quintana Prieto, El obispado de Astorga en los sigios ix y x. Astorga, 1968, pp. 334-336.

11 Id., pp. 336-337.

12 J. M. Minguez, Colección diplomática del monasterio de Sahagún, I (siglos Ix-x), León, 1977, pp. 170-171, no 132 .

13 Quintana: ob. cit., pp. 377-378.

14 R. Rodríguez, Catálogo de documentos del monasterio de Santa María de Otero de las Dueñas, Archivos Leoneses, 23, 1948, pág. 18, $\mathrm{n}^{\circ} 24$.

15 J. M. Ruiz Asencio, Colección documental del archivo de la Catedral de León (775-1230), III (986-1031), León, 1987, pp. 27-28, ํㅜㄴ 530.

16 Id., pp. $51-53, n^{2} 548$. 
llamadas Cazanuecos y Valdemiñín ${ }^{17}$; el 5 de septiembre del año 998 dona al cronista Sampiro, futuro obispo de Astorga, la villa llamada Altobar de la Encomienda ${ }^{18}$; y el 12 de noviembre del año 1000 Alfonso $\mathrm{V}$ dona a Froilán, obispo de León, una villa en Bustillo del Páramo ${ }^{19}$.

En principio, la mayoría de estas donaciones son, parecen ser, simples donaciones de bienes que cada rey dispone como cualquier otro propietario privado. Son los casos de los bustos, las villas-explotación y la iglesia de San Martín de Parada. Para la institución monárquica no suponen mella alguna de su soberanía, aunque para los receptores de las donaciones, miembros de la aristocracia laica y eclesiástica, son inversiones de futuro en casi todos los casos. Por una parte, les permite introducirse en las comunidades aldeanas donde están situados dichos bienes; por otra, sobre la propiedad de estos bienes podrán basar futuros derechos señoriales sobre sus colonos, incluso los habitantes de dichas comunidades. No parece descabellado pensar que en los dos bustos se asienten colonos formando pequeñas aldeas. En el donado por Ordoño II en 918 se indica que los hombres que allí fueren a poblar queden bajo la obediencia del donatario y le paguen el tributo correspondiente. La situación de dependencia de estos campesinos, al igual que los asentados en las otras villas donadas, es clara.

Cuando el objeto donado parece ser una aldea el análisis se complica, salvo en el caso de la desaparecida Orniola. Esta villa había sido una presura de Vermudo Gatóniz, un hịjo del repoblador de Astorga, que pasó a manos del rey García I. Es el típico caso de aldea nacida de la repoblación, cuyos habitantes mantienen con el propietario de la misma una vinculación personal en base a unas tierras que trabajan, por las que deben satisfacer ciertas contraprestaciones.

En las restantes donaciones no está tan claro el objeto jurídico entregado. Asi, en los casos de Matilla y Magretes, en 951, se indica que la primera de ellas es una villa propia con las típicas pertenencias: tierras, viñas, prados, etc. Lo cual da pie a pensar que no sea la propiedad de la aldea en sí sino algún tipo de jurisdicción - la propiedad señorial de la que habla $C$. Estepa- o la propiedad de los terrenos baldíos y de uso colectivo, ya que no se mencionan casas entre las pertenencias de la villa ${ }^{20}$.

17 Id., pp. 77-79, no 565 .

Id., pp. $97-101, n^{\circ} 581$.

Id., pp. 122-124, n² 599 .

J. M. MinguEz, «Antecedentes y primeras manifestaciones del feudalismo astur-leonés», en En torno al feudalismo hispánico, I Congreso de Estudios Medievales (1987), Ávila, 1989, pp. 85120 , concretamente en las páginas 115-116 señala esta posibilidad. 
Esta segunda posibilidad viene a encajar con el caso de Magretes, ya que unos años después el monasterio de Sahagún compra un monte y recibe varias tierras en dicho lugar ${ }^{21}$. De haber sido el propietario de dicha aldea no habría comprado estos bienes. Por lo tanto, la propiedad individual de cada vecino es respetada por el rey, que dona cierta jurisdicción sobre los habitantes del lugar o los derechos sobre los espacios de uso colectivo.

En las donaciones de aldeas enteras hechas por Vermudo II los documentos son algo más explícitos. Así, en el caso de Toral de los Guzmanes se indica que dicha villa incluye a todos sus habitantes y las prestaciones inherentes a ella. A pesar de que no se incluyan fórmulas relacionadas con las concesiones de inmunidad, esta donación parece que tiene que ver más con algún tipo de jurisdicción que con la propiedad en sí de la villa.

En el caso de la donación de Altobar de la Encomienda hay bastantes datos, ya que se indica que los hombres que en ella viven, y los que vengan, se incluyen en la donación. Por lo tanto, se puede tratar de colonos establecidos en una aldea, que, en este caso, es propiedad del rey tras confiscarla al rebelde Gonzalo Vermúdez. A ello se puede añadir cierto poder jurisdiccional sobre los colonos, ya que se indica que «licentiam tibi damus eos colligendi et tui arbitrii ad ovediendum jugandi». Así pues, a pesar de no aparecer las típicas fórmulas utilizadas en las concesiones de inmunidad hay indicios más que suficientes de que el donatario recibe algo más que la propiedad de la aldea.

Por último, la donación de Cazanuecos y Valdemiñín apunta hacia lo reflejado en el anterior ejemplo, ya que el receptor obtiene cierta jurisdicción — «pro homicidio aut pro rauso aut pro fossatariam aut pro aliqua re»-, además de la propiedad en sí de las dos villas.

En resumen, se aprecia cierta evolución en el contenido de estas donaciones reales. Las efectuadas en la primera mitad del siglo $x$ suelen ser explotaciones, casi nunca aldeas, mientras que en la segunda mitad generalmente son aldeas. No hay duda de que la crítica situación que atraviesa la monarquía durante este período provoca el aumento cuantitativo y cualitativo de estas donaciones. Como bien ha señalado J. M. Mínguez, la presión que ejerce la aristocracia sobre la monarquía es la principal demostración de la feudalización del reino ${ }^{22}$. Vermudo II intenta frenar los deseos

21 Mínguez: ob. cit. Colección Sahagún..., pág. 225, nำ181, en 960 le entregan tierras; pp. 315-316, n² 264, en 971 compra un monte. Estos documentos reflejan la implantación del monasterio en una zona concreta, vecina de Lampre-ana, donde también era propietario.

22 Minguez: ob. cit., Las sociedades feudales..., pág. 156. 
de la aristocracia entregando bienes a sus fieles, entrando en un círculo vicioso de rebeliones y constantes donaciones.

Aunque no son muchos ejemplos, parece claro que la aristocracia ya no se conforma sólo con acumular propiedades. Además de la presión sobre los colonos que viven en tierras de esta aristocracia, el resto de los campesinos comienzan, poco a poco, a caer en el entramado de vínculos y dependencias personales propios de las sociedades feudales, mezclándose lo público y lo privado.

A pesar de no ser donaciones reales directas algunos documentos de principios del siglo $x$ señalan claramente esta transición hacia el feudalismo. Así, con fecha del 26 de junio del año 917 el abad lquilani dona al monasterio de Santiago de León, entre otros bienes, tres villas sitas en Bercianos del Páramo, "cum homines habitantes et qui habitandum venerint, ad vestram concurrant precepta, patrocinium vobis prebeant et obsequium» ${ }^{23}$. Aunque sólo los habitantes de estas tres villas estén sujetos a estas condiciones, no todos los de Bercianos del Páramo, la tendencia que se apunta está clara, ya que el propietario parece tener más poder que el de un simple dueño de unas tierras. Sobre todo si se tiene en cuenta que la utilización de la fórmula "ad vestram concurrant precepta» suele relacionarse con concesiones de inmunidad.

También, ese mismo día Frunimio, el obispo de León, dona a la Iglesia de León, entre otros bienes, la villa llamada Bercianos - despoblado cercano a Carrizo de la Ribera-, indicando que sus habitantes deben pagar todos los años doce "modios de ordeo" y doce "vicinarios» de lino y prestar el servicio de seis rejas, además de entregar la heredad y la mitad de sus bienes personales en caso de que abandonen el lugar. Por último, se indica que las penas pecunarias de los delitos que cometieren pertenezcan a dicha iglesia ${ }^{24}$. Así, además de indicar la situación de los llamados más tarde «iuniores», el documento prueba la pérdida de soberanía por parte de la monarquía en fechas muy tempranas del siglo $x$, dando muestras de que el proceso de sometimiento del campesinado había comenzado muy pronto, con la repoblación misma del territorio por la monarquía astur.

La monarquía ha cedido parte de su poder a la aristocracia porque no le queda otro remedio ante las demandas de ésta durante la segunda mitad del siglo x. Gracias a la consolidación de un patrimonio territorial, este grupo puede presionar desde la óptica jurisdiccional -impartir justicia,

23 SÁEZ: ob. cit., pp. 68-70, no 42 .

24 Id., pp. 68-70, n 42 . 
cobro de multas y tributos- a los campesinos, colonos o no, para aumentar la llamada renta feudal. Así, acorde con los acontecimientos que están ocurriendo las únicas referencias documentales en las que aparecen miembros de la aristocracia relacionados con la jurisdicción judicial se producen a finales de siglo. Así, en 994 Froila Vimarédiz, "armiger regis", recibe de Muhagare y de su esposa Godina una viña en Villa Setimo, junto al río Órbigo, debido a cierto juicio celebrado ante los jueces del rey ${ }^{25}$; el 15 de septiembre del año 997, Hazeme y su esposa Felicia entregan al conde Munio Fernández la mitad de una heredad sita en la Bañeza, ya que habían perdido un juicio y no podían pagar lo estipulado ${ }^{26}$; y el 17 de abril del año 1003, es Auria la que entrega al mismo conde una villa en Santa Colomba de la Vega, ya que cometió fornicación con un hombre casado ${ }^{27}$.

Además de señalar la importancia que para la aristocracia tiene esta vía de acceso a la propiedad territorial, estos ejemplos reflejan los cambios que se están produciendo en la sociedad asturleonesa. El principal es el acceso de la aristocracia a cotas de poder antaño reservadas a la monarquía. La simple transmisión de poder puramente dominical, cuyas relaciones se mueven en una órbita jurídico-privada, ha sido superada por otra que desborda el ámbito privado al transferir funciones de orden público a un particular para su propio provecho. A pesar de los escasos datos documentados, en otras zonas cercanas al territorio astorgano está ocurriendo lo mismo, como no podía ser menos.

Junto a estas vías para la formación de la gran propiedad, la aristocracia también se dedica a comprar tierras y otros tipos de bienes gracias a sus posibilidades económicas y, sin duda, a las decisiones con que puede presionar a los campesinos, sobre todo en años de malas cosechas. A pesar de su procedencia casi exclusivamente eclesiástica, la documentación relativa al territorio astorgano también incluye algunos ejemplos de compraventas protagonizadas por laicos pertenecientes al grupo aristocrático y por otras personas que también parecen serlo, aunque no se indique directamente. Así, entre las más destacadas, en 29 de abril del año 958 el monasterio berciano de San Cosme y San Damián de Burbia compra una tierra Barrientos y una "senra" en Posadilla de la Vega, pagando cincuenta sueldos ${ }^{28}$; durante el año 962 , en seis ocasiones distintas,

Rodríguez: ob. cit., pág. 20, nº 29.

Ruiz AsEncio: ob. cit., pp. 94-95, nº 578.

Id., pp. 168-169, no 632 .

B.N., MS. 4357 , FOL. $39,^{\circ} 371$. 
el monasterio de San Adrián del Valle compra cinco tierras y un prado en la Ribera del Órbigo, pagando como precios una oveja con su cría, dos bueyes, tres bueyes, dos sueldos y cuatro sueldos ${ }^{29}$; en 11 de junio del año 971 el monasterio de Sahagún compra un monte en Magretes, pagando veinte sueldos ${ }^{30}$; en 972 el conde Nuño Sarracínez compra a Gaudioso y a su esposa Gudigeva una viña y un huerto en Colinas de Trasmonte, pagando una oveja, un carnero y un lienzo ${ }^{31}$; en 31 de octubre del año 999 Froila Vimarédiz compra una heredad en Posadilla de la Vega, pagando setenta sueldos ${ }^{32}$; y en 1 de octubre del año 1000 Vellida y su hijo Gonzalo compran dos heredades en la Ribera del Órbigo, pagando con un caballo, dos bueyes, 32 ovejas y diversas alhajas ${ }^{33}$.

Dejando a un lado las desconocidas causas coyunturales de cada caso, estos datos demuestran la imposibilidad de la gran mayoria de las personas para comprar algo más que una simple tierra. Además de algunos campesinos sólo los miembros de la aristocracia laica y eclesiástica están en condiciones de pagar estos precios. Con ello la compra de bienes - sobre todo los más apeticibles- prácticamente se convierte en un instrumento para dicho grupo de acceso a la propiedad territorial. Más para los laicos que los clérigos, que acumulan bastantes bienes gracias a las donaciones. En fin, es un complemento dentro del proceso de acumulación de bienes.

Finaimente, otra de las vías de acceso a la propiedad es la profiliación, institución cuyos orígenes romanos y gentilicios se entremezclan. Lo fundamental es que los actuantes hacen herederos a personas extrañas, que en la mayoría de los casos son aristócratas laicos y monasterios. Éstos en contrapartida suelen entregar animales o contraer algún tipo de vinculación personal.

Los escasos ejemplos documentados inciden en lo dicho en el párrafo anterior. Así, en 29 de octubre del año 960, Aveiza y su esposa Egelo hacen profiliación a favor del conde Nuño Sarracínez de la tercera parte de sus bienes en Colinas de Trasmonte ${ }^{34}$; en 23 de mayo del año 962, Fernando y su esposa María hacen lo propio a favor de la abadesa

29 B.N., ms. 4357 , fol. $43, n^{\circ} 511-516$.

30 Minguez: ob. cit. Colección Sahagún..., pp. 315-316, n²64.

31 E. SAEz y C. SAEZ SÁnCHEz: Colección documental del archivo de la Catedral de León (7751230), II (953-985), León, 1990, pp. 212-213, nº 420.

32 Rodríguez: ob. cit., pág. 20, nº 34 .

33 B.N., ms. 4357 , fol. $19, n^{\circ} 146$.

34 SÁez y SAez SÁnchez: ob. cit., pp. 109-110, $n^{\circ} 331$. 
Flamula de su heredad en Oncina, que a cambio entrega un caballo valorado en cien sueldos ${ }^{35}$; en 30 de abril del año [980-984], Romano y María hacen lo propio a favor del monasterio de Sahagún de cuanto poseen en Villa Bacrinis, cerca de Villaveza de! Esla, que a cambio entrega dos bueyes, diez ovejas, quince sueldos y una piel ${ }^{36}$; y en fecha indeterminada [989-1013], Zaide hace lo propio a favor del conde Munio Fernández de la mitad de su heredad en Ribas de la Valduerna, que a cambio entrega un potro y un yugo de bueyes ${ }^{37}$.

Aunque se hicieran profiliaciones entre personas de parecida condición social y económica, las que tienen que ver con la feudalización de la sociedad son las que se realizan entre pequeños propietarios y personas pertenecientes al grupo aristocrático, ya que superan la mera adquisición de los bienes por su valor intrínseco. Hay que verlas, una vez más, dentro del entramado social y económico de vinculaciones personales que caracterizan al feudalismo. La entrega de animales y otros bienes a los donantes asi lo confirman.

En resumen, diferentes vías utilizadas por la aristocracia para acceder a la propiedad dominical de la mayor cantidad de bienes, dentro de un proceso comenzado con la repoblación a mediados del siglo ix y que durante la segunda mitad del $x$ se acelera. Así, algunas donaciones con bienes repartidos por distintas comarcas del territorio astorgano, y fuera de él, demuestran el proceso de acumulación de la propiedad en manos del grupo aristocrático, ya sean heredados o comprados. Así, entre otros, en 13 de abril del año 943, Auria dona al monasterio de San Cristóbal de Astorga sus propiedades en Astorga, Requejo, el valle del Turienzo, Soguillo del Páramo, la Polvorosa y el Bierzo ${ }^{38}$; en 24 de junio del año 967 los hermanos Quilio y Abundas donan al mismo monasterio sus propiedades en Requejo, Gemelles, el Páramo, Andiñuela, Celadilla, Astorga, Priaranza y Quiros ${ }^{39}$; en 2 de agosto del año 977, Imilio dona al mismo monasterio sus propiedades en Quiros, Ozaniego, La Bañeza, Celada de la Vega, Requejo de la Vega, Villamontán de la Valduerna y Aureliano ${ }^{40}$; y en 8 de agosto del año 1003, Gaudino Lazáriz y su esposa Quiro donan al monasterio de San Salvador de Astorga dos casas con sus ajuares, unas

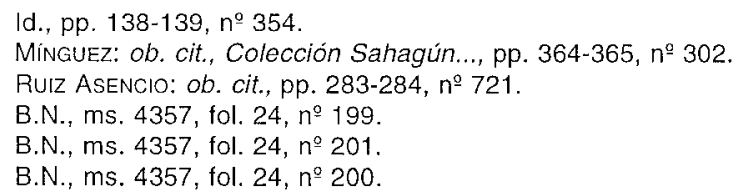


tierras en San Juan, la mitad de un molino que comparten con el monasterio de Samos, un soto junto al río Tuerto que comparten con el monasterio donatario, un quintanal que fue de Gómez Núñez, un prado comprado a su hermana Orbita por cincuenta sueldos y la mitad de la senra de Ero Malo ${ }^{41}$.

También, aunque dentro del siglo XI, se puede incluir entre estos ejemplos la repartición de bienes hecha entre los hijos del conde Munio Fernández hecha en 1016. Así, se citan San Lorenzo, Gigosos, Valdevimbre, Villacidayo, Cimanes de la Vega, Bariones, Santa Colomba de las Carabias, Matilla de Arzón, Toral de los Guzmanes, San Pelayo de la Valduerna, Orta, Asturianos, La Nora del Río, Bécares, Urdiales del Páramo y Villa Secundos del Páramo ${ }^{42}$. A estas villas, además, habría que unir otros bienes situados en La Bañeza, Manganeses de la Lampreana, Santa Colomba de la Vega y Ribas de la Valduerna ${ }^{43}$.

Datos como los presentados confirman el proceso de acumulación de bienes en diferentes comarcas y territorios por parte de personas pertenecientes al grupo aristocrático, que tiene como consecuencia la formación de la gran propiedad territorial, aunque dispersa y fragmentada normalmente.

Por importante que sea la acumulación de tierras es evidente que la dinámica que se crea entre la aristocracia territorial y los campesinos trasciende a la mera relación entre dueño y colono, y que algo más se está produciendo dentro de la sociedad, que llegado un momento en su evolución presenta a la aristocracia demandando a la monarquía una mayor cota de poder. Esto es, ceder parte de la soberanía del rey a la aristocracia. La primera consecuencia de este pulso es la grave crisis que atraviesa el reino durante las últimas décadas del siglo $x$, que sólo se resuelve, definitivamente, durante el reinado de Alfonso $\mathrm{V}$, tomando cuerpo en el Fuero de León (1017-1020): la sanción formal del feudalismo y su entramado de vinculaciones personales que provocan la confusión entre lo público y la privado.

Seguir este proceso de jerarquización de la sociedad, paralelo al de la formación de la gran propiedad, a través de la documentación astorgana es complicado, ya que los datos son pocos y fragmentados. Sólo durante la segunda mitad del siglo $\times$ se puede apreciar la actuación de la aristocracia

\footnotetext{
B.N., ms. 4357 , fol. $24 \mathrm{v}, \mathrm{n}^{\circ} 204$.

RUIZ AsENCIO: ob. cit., pp. 312-313, n²743.

Id., pp. 94-95, n² 578; pp. 129-130, n 605; pp. 168-169, no 632; pp. 283-284, n² 721 .
} 
-más la eclesiástica, aunque bastante más pasiva que la laica - en su conjunto. Así, metodológicamente hablando la documentación referente a algunos miembros de la aristocracia laica va a ser la base del estudio de este proceso de acumulación de poder económico, social y político de dicho grupo de la sociedad leonesa.

El conde Nuño Sarracínez es uno de los mejores ejemplos documentados de un personaje perteneciente al grupo aristocrático. Una primera mención a su persona se produce confirmando documentos cómo la donación realizada por Ordoño IV en $958{ }^{44}$. Seguidamente, en 29 de octubre del año 960, Aveiza y su esposa Egelo hacen «kartula perfiliationis» a favor del conde entregándole la tercera parte de toda su heredad situada en Colinas de Trasmonte ${ }^{45}$. También durante el año 960 recibe de Diego y de su esposa Jimena la mitad de una viña situada en Villanázar ${ }^{46}$. En 1 de marzo del año 962, Rauper y Mansuara le entregan una viña situada en Castroferrol, despoblado cercano a Colinas de Trasmonte ${ }^{47}$. Finalmente en 972, Gaudioso y su esposa Faquilo le venden una viña y un huerto situados en Colinas de Trasmonte, por los que paga una oveja, un carnero y un lienzo ${ }^{48}$.

No cabe duda de que estas actuaciones del conde Nuño Sarracínez no habrían sido las únicas, aunque las documentadas son suficientemente representativas. Éstas dan idea práctica del proceso de acumulación de bienes que la aristocracia realiza durante el siglo $x$. Aunque el valor intrínseco de los bienes no parezca ser muy importante es el conjunto de operaciones lo trascendente. Más si se tiene en cuenta un documento del año 1073 en el que una tal Orvellido Núñez dona al obispo de León, don Pelayo, la mitad de la villa llamada Colinas de Trasmonte, que le había correspondido de la herencia de su abuelo, el conde Nuño Sarracínez, «cum foro quale habuit cum illo comite, tam habitantes quam qui venerint ad habitandum, per suis terminis et divisionibus antiquis" ${ }^{49}$.

Conociendo este último dato se entiende perfectamente el modo de actuar de Nuño Sarracínez en Colinas de Trasmonte y sus alrededores. Como hay vecinos que son propietarios de sus bienes no parece que sea

44 QUintANA: ob. cit, pp. 377-378. Dona un busto situado en Alcoba de la Ribera.

SÁEZ y SÁEZ SÁNCHEZ: ob. cit., pp. 109-110, nº 331.

Id., pp. 117-118, nํㅡㄴ 335 .

ld., pág. $138, \mathrm{n}^{2} 353$.

Id., pp. 212-213, nำ 420 .

J. M. Ruiz Asenclo, Colección diplomática del archivo de la Catedral de León (775-1230), IV (1032-1109), León, 1989, pp. 432-434, nº 1186. 
del conde la propiedad de todo el lugar. Lo más normal es que tuviera cierto poder jurisdiccional sobre los habitantes, o incluso sobre los espacios baldíos de explotación comunitaria. Por to tanto es normal -en una sociedad en tránsito hacia e feudalismo- que un matrimonio del lugar haga heredero al conde a través de una profiliación y otras dos parejas le den -en los documentos sólo se habla de donaciones-algunos bienes, aunque sean poco relevantes. Estos hechos no se pueden entender más que en el marco de una sociedad en la que se están imponiendo las vinculaciones personales privadas al margen de las públicas. Así, solamente en este contexto no extraña que algunos campesinos entreguen parte de sus bienes a otro particular, a cambio de una contraprestación, que no se indica.

En este caso el proceso feudalizador no parece basarse en la previa propiedad del espacio, aunque la imposibilidad de conocer al detalle las características del «foro» que tenía el conde sobre Colinas de Trasmonte deja abierta la puerta de un previo dominio territorial de éste en dicho lugar. Por lo tanto, en este caso concreto hay más posibilidades de que una donación monárquica hubiera dado al conde cierto dominio sobre sus habitantes. De una forma o de otra los habitantes de Colinas de Trasmonte, y por cercanía los de las aldeas vecinas, entran en una dinámica de sometimiento gradual hacia el señor de turno, que acaba aglutinando poder territorial y señorial, en definitiva feudal.

En la figura de Ablavel Godesteoz no se aprecia con tanta claridad lo apuntado en el caso del conde Nuño Sarracínez, aunque no deja de aportar información sobre el proceso de feudalización de la sociedad astorgana, en particular, y leonesa, en general. Este personaje también está incluido dentro del grupo aristocrático, ya que tiene un buen número de bienes dispersos por diversas zonas del reino. Así, en 27 de noviembre del año 987 dona al monasterio de Sahagún una villa llamada Manzules, situada junto al río Cea, que había sido de sus padres; Villaordoño de Órbigo; Posadilla, en Campo de Toro; Villaverde con la villa de Partemio, en Fosinos; una villa en Villamorico, en el Páramo; otra villa en Valdejunco, en Lampreana; casas y viñas en Zamora; además de diversos bienes muebles y animales ${ }^{50}$. Algo después, en 19 de enero del año 990 , dona al monasterio de Santiago de Peñalba unos molinos situados junto al río Órbigo ${ }^{51}$.

\footnotetext{
Mínguez: ob. cit. Colección Sahagún..., pp. 401-402, nำ 333.
}

B.N., ms. 4357, fol. $19, n^{0} 148$. 
Más importante es una permutación de bienes, sucedida en 11 de septiembre del año 1001, en la que se dice que Ablavel Godesteoz había recibido de Ramiro III una villa en Manganeses de la Lampreana, que después entregó "per kartula scriptam firmitatis», ya que era su señor, a Fortes Didaz ${ }^{52}$. De ello se desprende que este último era vasallo de Ablavel Godesteoz. Por lo tanto, la jerarquización de la sociedad, cada vez más verticalizada en sus relaciones personales, tiene un nuevo ejemplo a principios del siglo $\mathrm{XI}$.

Por lo que a Froila Vimarediz concierne, este hombre aparece como "armiger regis" en un documento del año 989 en el que Vermudo II le dona una heredad en Antoñán del Valle ${ }^{53}$. Posteriormente tiene otras apariciones en la documentación. Así, en 994, Muhagare y su esposa le entregan una viña situada en Villasetimo, junto al río Órbigo, tras un juicio celebrado ante los jueces reales ${ }^{54}$; en 6 de junio del año 995, Vegilio y su esposa Gunterodo le donan otra viña situada en Posadilla de la Vega, y doña Bona y su hijo hacen lo propio con la tercera parte de su heredad en el mismo lugar ${ }^{55}$; y en 31 de octubre del año 999, Vidozoi y Alveizon le venden una heredad situada en Posadilla de la Vega, a cambio de setenta sueldos ${ }^{56}$.

Al igual que en los anteriores casos los documentos relativos a Froila Vimarediz reflejan una vez más a un miembro de la aristocracia acumular bienes gracias a diversos cauces, los más importantes vedados para la mayoría de los habitantes del reino. Así, además de la donación real, los bienes obtenidos de los presumiblemente pequeños propietarios responden a algún tipo de relación personal entre dos particulares, en la que los campesinos entregan a un miembro de la aristocracia algún bien a cambio de algo. Como ocurría en el caso de Nuño Sarracínez, parte de la acción - seguro que tendría más bienes en otras zonas del reino- se centra en un espacio muy concreto donde $\in$ s posible que el aristócrata de turno tuviera algún tipo de poder señorial. En definitiva, acumulación de bienes gracias a las donaciones reales y a la presión sobre el campesinado.

Finalmente, aunque la mayoría de sus actuaciones tienen lugar durante el siglo Xl, el conde Munio Fernández es otro de los magnates que muestra el comportamiento de la aristocracia, en un momento además en

\footnotetext{
52 Ruiz Asencio: ob. cit. Colección León lll..., pp. 129-130, n²605.

Rodriguez: ob. cit, pág. $18, n^{\circ} 24$.

Ib., pág. 20, nº 29.

lb., pág. $20, n^{\circ} 31$.

lb., pág. $20, n^{\circ} 34$.
} 
el que la monarquía peor lo está pasando, ya que la documentación tiene ejemplos de todo tipo. Así, entre otras, en 23 de diciembre del año 989, Vermudo II le entrega Toral de los Guzmanes ${ }^{57}$; en 15 de septiembre de 997, Hazeme y su esposa Felicia, en concepto de «iudicato», le entregan la mitad de una heredad sita en La Bañeza ${ }^{58}$; en 15 de abril del año 1000 el magnate Fernando Núñez le vende, por doscientos sueldos, la villa llamada Oncina ${ }^{59}$; en 31 de mayo del mismo año permuta dos heredades en San Pelayo de la Valduerna ${ }^{60}$; en 11 de septiembre del año 1001 permuta bienes en Manganeses de la Lampreana y en Mansilla del Páramo ${ }^{61}$; en 17 de abril del año 1003, Auria y sus hijos, en concepto de «iudicato», le entregan su heredad en Santa Colomba de la Vega ${ }^{62}$; en 19 de febrero del año 1008 se le confirma la propiedad o el dominio señorial de San Pelayo de la Valduerna ${ }^{63}$; y en fecha indeterminada [989-1013], a través de una profiliación, recibe media heredad en Ribas de la Valduerna ${ }^{64}$. También hay que en un documento del año 1043 se indica que Vermudo II le había donado las villas llamadas Cimanes de la Vega y Matilla de Arzón ${ }^{65}$.

A la vista de estos datos, que otros magnates del reino repiten en otras zonas del reino, queda claro lo que supone a finales del siglo $x$ tener la posición económica y social de un aristócrata como el conde Munio Fernández. Lo cual le permite acumular un gran número de propiedades - heredades- y el dominio jurisdiccional de numerosas aldeas ${ }^{66}$, siendo una ve $\angle$ más las donaciones reales y la presión sobre los pequeños propietarios las vias que cualitativamente son más importantes dentro del proceso de feudalización de la sociedad para consolidar la posición económica y social de la aristocracia. No obstante, hay que indicar que los precios que se pagan por tierras sueltas o por villas casi siempre están lejos de las posibilidades de cualquier campesino, que debe limitarse, cuando fuera posible, a pequeñas compras que redondeen sus heredades. Nunca es un medio para acumular una gran extensión de terreno $o$ adquirir un status social privilegiado. Sólo una herencia, una acción guerrera, un matrimonio o el favor del rey lo permitirían.

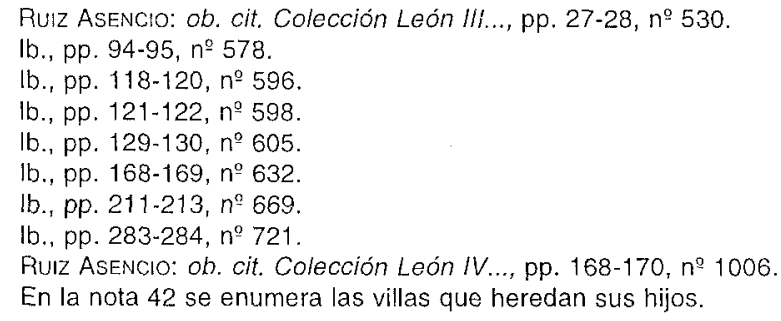


Según los datos obtenidos de este grupo de magnates pertenecientes al grupo aristocrático, que parece reflejar la actuación común del grupo social en el que se integran, en la segunda mitad del siglo $x$-principalmente a finales de dicho siglo y principios del siguiente-, hay unos modos de comportamiento bastante típicos de las sociedades feudales: protagonismo del grupo aristócrata, sometimiento del campesinado; creciente confusión entre lo público y lo privado; y creación de un entramado de vinculaciones personales, de índole vasallático-beneficial entre las personas del grupo aristocrático, en una sociedad cada vez más vertical.

La aristocracia del reino leonés es responsable de esta situación, aunque el rey y los campesinos también presten su colaboració, ciertamente involuntaria en el caso de los segundos. La monarquía astur, desde su creación, no había sido una institución totalmente estable. Aunque al final se mantuviera en ella la dinastía de Pedro de Cantabria, las crónicas dan noticia de diversas rebeliones y usurpaciones en casi todos los reinados. Lo preocupante es que éstas se produzcan todavía en el siglo $x$, cuando parecía que Alfonso III había consolidado ya la institución monárquica, liberándola de las luchas entre las diversas familias de la aristocracia indígena, más preocupadas en su expansión por el valle del Duero. Ello, sin duda, es producto de la transitoriedad que caracteriza este período histórico.

Cierta o no la rebelión de los hijos de Alfonso III, las luchas entre los nietos de éste reflejan la inestable situación en el grupo de poder de la sociedad astur. Así, tras el compás de espera que supone el reinado de Ramiro II, al que ya se le rebelan los condes castellanos - Ordoño II también había tenido problemas con los condes castellanos-, el grupo aristocrático rompe el fuego durante la segunda mitad del siglo $x$. Los condes y magnates actúan por cuenta propia apoyando a uno de los candidatos al trono o aliándose con el enemigo musulmán. Los reyes intentan mantener la fidelidad de la aristocracia a base de donaciones, entrando en un proceso de decadencia material y moral que roza los abismos con Vermudo II. No es extraño que sea el rey que más donaciones haya dejado documentadas en proporción a los años que reinó. Como ya se ha dicho anteriormente la situación de inestabilidad no cesa hasta que monarquía y aristocracia no pactan un arreglo. Ello significa que la monarquía renuncia a su concepción del poder, haciéndose feudal, y cede parte del poder a la aristocracia, que ya tiene el camino completamente libre para someter al campesinado y poder continuar un proceso iniciado tiempo atrás ${ }^{67}$.

67 Mínguez: ob. cit. Las sociedades feudales..., pág. 156. 
En la relación de documentos relativos a los cuatro magnates se ha visto la importancia de las donaciones reales en el proceso de creación de la propiedad territorial. Su influencia ha sido mayor a medida que la presión sobre la monarquía aumentaba, siendo el reinado del mencionado Vermudo II una época favorable para las donaciones reales, aunque bastantes de estas incluyeran bienes confiscados a los rebeldes. Éstas, además de incluir tierras, dejan entrever cierto dominio señorial sobre los campesinos ${ }^{68}$, al igual que otras donaciones hechas en la primera mitad del siglo $x$, aunque en número menor.

Siendo este apoyo de la monarquía decisivo a la hora de favorecer el proceso de sometimiento del campesinado no hay que olvidar el papel que juega en dicho proceso la evolución interna de las comunidades de aldea. Gracias a los estudios realizados en las últimas décadas los campesinos han dejado de ser esas figuras casi decorativas que se limitaban a seguir a un grupo de guerreros en su lucha contra los enemigos del sur. Según A. Barbero y M. Vigil los grupos gentilicios de la zona cantábrica formaron comunidades de aldea en las que primaban todavía los vínculos en razón del parentesco, manteniendo un fuerte componente matriarcal, que hacia los siglos VIII y IX comienzan un proceso de descomposición ${ }^{69}$. Además de su propia evolución interna, la causa principal es la expansión por el valle del Duero; su consecuencia más estética es la creación de una gran red de pequeñas aldeas, nuevas comunidades, en la vertiente septentrional del valle.

Dejando a un lado la cuestión del grado de participación de la monarquía astur en este movimiento expansivo, las comunidades de aldea son el eje del proceso colonizador. Estas villas, que en muchas ocasiones no pasarian de ser la unión de varios caseríos, agrupan a unos campesinos unidos por los lazos de vecindad, salvo en las aldeas de fundación familiar o señorial ${ }^{70}$. La documentación de finales del siglo $x$ y principios del $x$ muestran unas aldeas en las que el espacio se divide en zonas de propiedad privada - casa, tierras de labor y viñas, principalmente-y de uso colectivo, dedicadas a labores ganaderas, de recolección silvestre, suministro de leña, etc. Cada vecino dispone de su explotación y puede hacer lo que quiera con ella, cuando es su propietario. A pesar de ello, quizás como muestra de una evolución lenta hacia formas individualizadas,

63 ESTEPA: ob. cit, pág. 162. Habla de cierto poder jurisdiccional poco definido sobre campesinos independientes que estarian bajo cierta dependencia vasallática de un señor.

69 Barbero y Vigil: ob. cit. Formación del feudalismo..., pp. 370-371.

70. Muchos de los antropónimos pueden deberse a este tipo de creaciones. 
durante buena parte del siglo $x$ las ventas y donaciones de los miembros de las comunidades de aldea tienen el visto bueno de la «collatio». El hecho de que estas menciones desaparezcan de la documentación desde finales del siglo x plantea algunos interrogantes, aunque su relación con el proceso de feudalización de la sociedad parece claro. Sin duda el permiso de la comunidad para permitir que un extraño se introduzca en ella se debe al control de los espacios baldíos.

No acaba de estar claro el status jurídico de estos espacios. La monarquía reclama el dominio eminente de todas las tierras; las comunidades disfrutan de unos derechos de uso y propiedad difusos y complicados de delimitar ${ }^{71}$. El caso es que son la clave del desarrollo posterior de las aldeas, ya que permiten nuevas roturaciones y asentamientos humanos a medida que se produce la fragmentación de las explotaciones familiares y el crecimiento demográfico.

No cabe duda de que las ventas, donaciones, pagos y profiliaciones que hacen los campesinos a los miembros de la aristocracia -incluidos los pequeños monasterios - provocan la ruptura de la unidad de estas comunidades y su disolución ${ }^{72}$. La otra vía es la propia jerarquización interna de estas comunidades ${ }^{73}$. Pero el tiro de gracia se lo dan las donaciones que los reyes hacen de aldeas enteras. Ya sea el control de los espacios baldios, cierto poder señorial sobre los habitantes o incluso la propiedad territorial del lugar, los habitantes de la aldea en cuestión, a nivel individual o comunitario, quedan bajo la dependencia de un señor.

Lo que esta losa supone para el campesinado está claro: relación de dependencia, pagar una serie de tributos y trabajar en las tierras del señor. Esto es lo que la historiografía que estudia el feudalismo desde una perspectiva globalizadora, analizando factores politicos, sociales y económicos, ha llamado renta feudal. Ésta se establece como consecuencia de la articulación de unas relaciones sociales de producción, que desgraciadamente son difícil de seguir ya que la documentación de esta época no

71 Minguez: ob. cit. Las sociedades feudales..., pág. 140.

72 Estepa: ob. cit. Formación y consolidación..., pp. 192-196, habla de varias vías para su disolución: concentración de la propiedad de los campesinos en favor de los poderosos, sujeción de la comunidad a un poderoso, encomendación o profiliación, ejercicio de poder económico y político sobre una mandación y proceso de disolución interna.

73 Asi lo señalan, entre otros: REYNA PASTOR DE TOGNERI: Resistencias y luchas campesinas en la época del crecimiento y consolidación de la formación feudal. Castilla y León. siglos $x-x i l$, Madrid, 1980, pág. 37; J. M. Mínguez, ob. cit. Antecedentes del feudalismo..., pág. 107; y J. A. Garcia de CORTÁzAR, La sociedad rural en la España medieval, Madrid, 1990, pág. 29. La documentación astorgana no aporta ejemplos de la jerarquización de las comunidades. 
aporta apenas datos, y los que hay son casi todos genéricos. Uno de los que habla con más claridad es una donación del año 917 en la que se indica que los campesinos instalados en una villa propiedad del obispo de León deben pagar doce «modios de ordeo» y de lino, además de hacer seis «rejas» en las tierras del obispo cada año ${ }^{74}$. Obviamente no todas las aldeas sufren esta situación durante el siglo $x$, aunque la tendencia está clara. Las donaciones de bienes y las concesiones de inmunidad dadas por los reyes aumentan progresivamente durante este siglo, sobre todo en el último tercio, creando verdaderos antecedentes de los señoríos jurisdiccionales bajomedievales, además de desarrollarse figuras jurídicas como la benefactoria, que en resumidas cuentas es un señorío atenuado por cierta libertad para elegir al señor de turno.

Es en este contexto de finales del siglo $x$ donde se encuadran esas compras, donaciones, cobros de delitos y profiliaciones que protagonizan el grupo de aristócratas anteriormente detalladas. Sólo la inseguridad y la mala situación económica, además de otras causas coyunturales, pueden explicar que dichos magnates reciban donaciones y profiliaciones y cobren multas de unos campesinos, por lo general pequeños propietarios, que miran a la persona con poder que más cerca tienen. Parece claro que los caracteres de las sociedades feudales están bastante arraigados a finales del siglo $x$, aunque se desarrollarán plenamente a partir del siglo XI.

Que el proceso de acumulación de tierras protagonizado por la aristocracia en detrimento de los campesinos responde a algo más que a la mera acumulación de bienes lo prueba el número de litigios que desde las últimas décadas recoge la documentación. Aunque la situación de crisis casi permanente que vive el reino durante los últimos años del siglo $x$ provoca la usurpación de bienes abandonados y otras situaciones parecidas, algunos ejemplos reflejan un estado mental propio de situaciones crispadas. Así, en 12 de mayo del año 994, Jimeno, obispo de Astorga, dona a unas religiosas huidas, sin duda de los ataques de Almanzor, el monasterio de San Julián de Vime de Sanabria, que había pertenecido a fray Abdelón, que después de pleitear con un tal García Fernández lo perdió tras un asalto ${ }^{75}$.

En 19 de febrero del año 1008 el conde Munio Fernández es acusado por el obispo de Astorga de haber quitado a una hermana de éste la villa

74 SÁEZ: ob. cit., pp. 70-72, $n^{\circ} 43$. Se indica que los campesinos que abandonen el lugar, llamado Bercianos, deben entregar toda la heredad y la mitad de sus bienes personales.

75 B.N., ms. 4357 , fol. $51 \mathrm{v}, \mathrm{n}^{\circ} 583$. 
llamada San Pelayo de la Valduerna, tras haberla encarcelado y forzado a entregar la villa al conde ${ }^{76}$. Finalmente éste prueba que se había limitado a comprar dicha villa a la hermana del obispo, pagando 250 sueldos. Es de suponer que al conde no le haría mucha gracia la acusación del obispo.

Aunque se produce en el año 1014 hay un litigio entre un magnate, Pelayo Daniéliz, y el monasterio de Santa Marta de Tera, una de las instituciones religiosas más importantes del territorio astorgano, que muestra la mentalidad de las personas a principios del siglo xI. Así, el monasterio tiene que entregar a Pelayo Daniéliz media alanzada de viña y la parte de un prado y una tierra situados junto al arroyo del Regato, cerca del río Tera, que habían sido de Ambrosio Ropáriz y Alfonso $V$ había dado al citado Pelayo Daniéliz ${ }^{77}$. En principio no parece que hubiera confusiones - el monasterio está bastante cerca de lugar y Pelayo es oriundo de la zona- ni que los bienes merecieran tales preocupaciones, pero...

En definitiva, la sociedad que se ve reflejada en la documentación apunta unas maneras de actuar claramente feudales, cuyas características principales son un grupo aristocrático cada vez más poderoso - en todos los aspectos - y un campesinado cada vez más sometido por el grupo citado.

Hasta este punto la aristocracia ha estado representada generalmente por su sector laico, aunque el eclesiástico también se beneficie de la marea feudal, sobre todo la jerarquía de obispos y los grandes monasterios del reino, que mantienen con la monarquía una relación recíproca de ayuda y apoyo. Salvo excepciones, la jerarquía eclesiástica no participa en las constantes rebeliones de la aristocracia laica contra la monarquía durante la segunda mitad del siglo $x$, aunque acabe beneficiándose de la situación. No hay más que ver las primeras disposiciones del Fuero de León y las cuantiosas donaciones que reciben las sedes episcopales y los monasterios más importantes.

Por lo que al territorio astorganc se refiere, la restauración del antiguo obispado de Astorga conlleva la entrega a éste de una gran extensión de tierras, generalmente concentradas en las comarcas más cercanas a Astorga: Somoza, Cepeda y el valle del río Tuerto, quizás porque la repoblación oficial no llega al Duero hasta el siglo $x^{78}$. Con esta primera concesión real, y con posteriores, la Iglesia diocesana de Astorga obtiene

76. Ruiz Asencio: ob. cit. Colección León III..., pp. 211-213, no 669.

77 B.N., ms. 4357 , fol. $15, \mathrm{n}^{\mathrm{O}} 106$.

79 Así se deduce de posteriores documentos que demuestran la existencia de un importante patrimonio de la sede astorgana en las comarcas más cercanas al Bierzo. 
un extenso, aunque disperso, patrimonio dominical, como ocurre con las demás sedes en sus respectivas diócesis. Desde este mento el modo de actuar de los obispos astorganos depende -eso parece-más de la persona que del contexto en que se mueven, aunque muchos de ellos pertenezcan a familias de la aristocracia astur, cosa normal en esta época.

Indisclo, el que parece ser el obispo que acompaña al conde Gatón cuando la monarquía astur realiza la repoblación de Astorga ${ }^{79}$, se comporta como un magnate laico más. Así, gracias a documentos posteriores se conocen sus presuras en Brimeda ${ }^{80}$ y en Parada y Cebraria ${ }^{81}$, bajo el control y dirección de Gatón. Además, utiliza su patrimonio personal y el de la diócesis como si fueran uno solo. Esta confusión jurídica es sin duda reflejo de lo que está ocurriendo con la aristocracia laica que ha conseguido que el rey le encargue el gobierno de un territorio de su cada vez más grande reino, y que luego incluye entre su patrimonio particular, vinculándolo a su linaje, caso de algunos condados castellanos.

En su relación con el monacato hay un dato significativo. Tras la muerte de los abades fundadores del monasterio berciano de Santa Leocadia de Castañeda sus moradores se dividieron, entregando al obispo Indisclo una parte de éstos el pacto fundacional del monasterio. El obispo cerró la disputa vinculando el monasterio a su sede ${ }^{82}$.

Este episodio parece uno más, aunque temprano, del deseo de los obispos por extender su dominio a la multitud de fundaciones religiosas privadas que se habían realizado, y se estaban realizando, con anterioridad a la restauración del obispado astorgano. Como el Bierzo estaba incluido en este obispado hay que suponer que esta comarca no tuvo una adscripción eclesiástica previa a la repoblación. Por lo tanto, la construcción de iglesias y monasterios estuvo desvinculada de la jerarquía eclesiástica, que más tarde intentó recuperar el terreno. Esto es, el poder de su antecesora, la jerarquía visigoda, de la que, al igual que la monarquía astur de la monarquía toledana, decían ser sus herederos.

No cabe duda de que esta actitud de los obispos astures -en este caso astorganos - tiene que ver más con intereses materiales -control

\footnotetext{
79 QuinTANA: ob. cit., pp. 9-21.

so Id., pp. 33-35. Se trata del famoso pleito por Brimeda entre Indisclo y los hijos de Catelino

81 B.N., ms. 4357, fol. 17, n² 131. En 894 Alfonso III compró esta villa a un sobrino del obispo.

82 QuinTANA: ob. cit, pág. 30.
} en 878 . 
de los bienes dados y de las tercias- que espirituales. Además, en el caso de Indisclo la sintonía con la mentalidad de la aristocracia laica es coincidente.

Los siguientes obispos mantienen mejores relaciones con el monacato de su diócesis, gracias a que muchos de ellos provienen de él. Así, Ranulfo promueve, junto al futuro obispo Genadio, la reconstrucción del monasterio de San Pedro de Montes, al que dotan con varias villas ${ }^{83}$, además de no vincularlo patrimonialmente a la sede astorgana.

Genadio, además de participar directa e indirectamente en la fundación de un gran número de monasterios -entre otros, Santiago de Peñalba, San Andrés de Montes, San Miguel de Escalada y San Martín de Castañeda ${ }^{84}$ - deja claro que proviene del mundo monacal —no duda en renunciar al puesto de obispo para retirarse al Valle del Silencio, en plenos montes de León-, ya que entrega a los propios monjes los cenobios fundados por él, incluso devuelve a los monjes del monasterio de Santa Leocadia de Castañeda sus derechos de propiedad ${ }^{85}$.

Por otra parte, las donaciones que hace a los demás monasterios son con la intención clara de consolidar la fundación y mantener un nivel económico que no les haga depender de nadie ${ }^{86}$. Esta forma de actuar, positiva para los monasterios, también está en consonancia con la mentalidad de la época. El obispo utiliza los bienes de su sede para favorecer sus fundaciones, creando unos vínculos con ellas, aunque más espirituales que materiales. Esto es debido al carácter del obispo, ya que en otros casos se intenta una dependencia de las sedes episcopales en todos sus aspectos.

Los obispos que le siguen en el cargo también provienen del monacato, aunque no todos. Sin llegar a los niveles de Genadio la relación de sus sucesores con el monacato es buena, no habiendo constancia de presiones a los monasterios.

Más importantes son los mandatos de Gonzalo y de Jimeno, ya que en el último tercio del siglo $x$ la crisis se agudiza. Se produce el enfrentamiento

83 1d., pp. 57-64, recoge donaciones de los años 892, 895, 896 y 902.

84 ld., pág. 161.

85 Id., pp. 205-207. En 8 de enero del año 916. Además le entrega dos villas, que sin duda pertenecian a la sede astorgana.

86 Id., pp. 207-210, en 920 a los monasterios de San Pedro de Montes, San Andrés de Montes y Santiago de Peñalba; pp. 211-212, en 920 al monasterio de Peñalba y a los eremitas del valle del Silencio. 
entre Ramiro III y Vermudo II, los ataques de Almanzor a Astorga y las rebeliones de los miembros de la aristocracia. A pesar de lo crítico de la situación estos obispos mantienen su fidelidad a la monarquía.

Por lo que se sabe Jimeno se muestra como un hombre de su tiempo. No duda en luchar para defender al rey o recuperar bienes de su sede usurpados. Por otra parte, realiza importantes donaciones de su patrimonio personal a su sede y a distintos monasterios. Asi pues, se nota cierta evolución entre los primeros obispos, vinculados al monacato y con patrimonios personales normales, y este último. La documentación refleja la posición de Jimeno dentro de una sociedad cada vez más feudalizada. Así, en 29 de marzo del año 992, al mes de ser nombrado obispo, un tal Guivaria le entrega su heredad en Santa María de la Vega a cambio de un cabalio y de manutención y ropa de por vida ${ }^{87}$; en 6 de septiembre del año 1001 el presbítero Fagildo, tenente de Astorga, entrega al obispo Jimeno una heredad, ya que se había negado a «juntar gente» para ayudar a Alfonso $V$, como le había ordenado el obispo ${ }^{88}$; y en 15 de febrero del año 1015 dona a la sede astorgana una importante serie de bienes: el masterio de Pradilla de Sil, que encontró desierto; una villa en Verdenosa - Santa María de la Vega-; otra villa en Ribarroya, que le entregaron como de un préstamo previo; además de otras en Seval, Manganeses de la Polvorosa, Paladinos, Mayorales, Barreca, Piedras Albas y Boeza ${ }^{89}$. A esta lista se podrían añadir otras villas donadas a los monasterios de San Dictino de Astorga, Sahagún y Santiago de León.

Los datos aportados muestran a un obispo actuando en una sociedad cada vez más feudalizada, que acumula un gran patrimonio a través de muy distintos medios, del mismo modo que lo hacen los miembros de la aristocracia laica. Además, el poder político que goza es superior al que en teoría debía tener un obispo, sobre todo los primeros obispos astorganos.

En cuanto a los monasterios astorganos, hay que diferenciar entre los situados en Astorga y los rurales. Estos últimos tienen su origen en fundaciones privadas enmarcadas dentro del proceso repoblador y colonizador, sobre todo hasta la primera mitad del siglo $x$. Algunos de ellos se consolidan y con los años acumulan cierto patrimonio gracias a las donaciones de medianos y pequeños propietarios residentes en sus cercanías. La mayoría de estos monasterios dejan de recibir donaciones durante las

87 B.N., ms. 4357 , fol. $48, n^{\circ} 551$.

s8 B.N., ms. 4357 , fol. $48 \mathrm{v}, n^{\circ} 544$.

89 B.N., ms. 4357 , fol. $49, n^{\circ} 548$. Demuestra la gran actividad de este obispo. 
dos últimas décadas del siglo x por razones obvias. Además, durante los primeros años del siglo $\mathrm{xI}$ tienen que litigar en muchas ocasiones para recuperar bienes usurpados durante los años de crisis. Sólo uno o dos terminan consolidándose como grandes propietarios; el resto acaban vinculados a la sede astorgana.

Los monasterios urbanos astorganos tienen su origen, en general, en el proceso repoblador protagonizado por gentes mozárabes. Todos consiguen su patrimonio gracias a las donaciones de grandes y pequeños propietarios, además de algunas compras, siendo los monasterios de San Dictino y de San Cristóbal los que más se benefician de este proceso.

En resumen, la actividad socioeconómica de la inmensa mayoría de los monasterios astorganos se desarrolla durante el siglo $x$ en un plano secundario respecto a la aristocracia laica, que es la que marca la pauta con su influencia. No parece que tengan mucho que ver con otros monasterios, caso del de Sahagún, que convertidos en grandes propietarios articulan sus bienes bajo una eficaz organización político-administrativa. Sólo el grupo formado por el obispo y unos pocos monasterios parece funcionar de igual manera que la aristocracia laica en sus propiedades. Otros tendrían que esperar los mejores tiempos del siglo xI.

En muchos casos, hablando del obispo de Astorga, se ha visto que utiliza el patrimonio de la diócesis como si fuera su propiedad particular. Donan, intercambian y venden bienes con laicos y eclesiásticos en un intento de acumular mayor poder o entablar algún tipo de vinculación personal. En realidad es la misma manera de actuar de la aristocracia laica y de las personas que viven en una sociedad en transición hacia el feudalismo en la que todavía no se ha planteado el problema de las iglesias particulares, que escapan al control episcopal.

\section{CONCLUSIÓN}

Este rápido repaso al proceso feudalizador de la sociedad astorgana corrobora que la transición hacia el feudalismo desde sistemas esclavistas y gentilicios estaba muy avanzada durante el siglo $x$. Elementos típicamente feudales que ya se habían dado en el período visigodo como las vinculaciones personales, la concesión de tierras en pago a servicios prestados y la adscripción del campesinado a la tierra también aparecen reflejados en la documentación de principios del siglo x. Lo cual no quiere decir que estuvieran plenamente desarrolladas y extendidas, aunque sí marcan las tendencias que se están produciendo en una sociedad en la que la 
propiedad privada, la familia nuclear y la economía basada en un equilibrio entre la agricultura y la ganadería son sus elementos más característicos.

La transición hacia el feudalismo ha acelerado su culminación, principalmente, durante la segunda mitad del siglo $x$ debido a la presión del grupo aristocrático, sobre todo de los grandes magnates leoneses, gallegos y castellanos, que no se contentan ya con la obtención de una impotante propiedad territorial y la administración de una demarcación en nombre del rey. Desean obtener poder político a costa de la figura del rey. Evidentemente, la concepción que cada uno tiene del poder monárquico provoca un duro enfrentamiento hasta que Alfonso $\mathrm{V}$ asume las pretensiones de la aristocracia, sancionando la nueva organización en el Fuero de León. A partir de este momento la monarquía no se verá atacada por ese flanco hasta siglos posteriores, ya que, entre otras razones, puede canalizar la agresividad de la aristocracia en la empresa conquistadora. Otra cosa serán las luchas entre distintos pretendientes al trono.

Aunque la aristocracia acelerara el proceso, hay datos - siempre son pocos- que confirman la participación directa de los campesinos en él. Éstos, agrupados en comunidades de aldea, están inmersos en un proceso de sometimiento que ha comenzado con la repoblación que de Astorga y su territorio ha hecho la monarquía astur. Así, mientras que un importante número de campesinos tiene la condición de propietario, la aristocracia laica y eclesiástica recibe de la monarquía grandes extensiones de tierras donde acaban asentándose colonos en situación de dependencia junto a los que en ellas ya debían de estarlo. Además, algunos magnates que gobiernan territorios en nombre del rey consiguen vincular el cargo a su familia y hacerlo hereditario, como ocurre en las zonas del reino más alejadas de la capital leonesa, reservándose las funciones públicas para ellos, con lo que esto supone para los campesinos. En la zona astorgana, en cambio, esta situación no ocurre, ya que el condado astorgano no se vincula a linaje alguno.

La documentación fechada en la primera mitad del siglo $\mathrm{x}$ refleja este proceso de feudalización. Por una parte, de modo general, la aristocracia -más la eclesiástica que la laica por mor de la documentación- ya se significa con sus importantes patrimonios, aunque dispersos. Herencia, compra o donación son las principales vías para su obtención. Por otra, las comunidades de aldea dependientes ya están sufriendo la presión de la aristocracia, aunque sean los propios campesinos los que en muchos casos la provoquen -inseguridad - al donar sus bienes a una institución religiosa o venderlos a otro laico. 
Más o menos desde mediados de siglo la documentación se hace más diversa y compleja. Aparecen donaciones reales en las que no queda claro si se dona la propiedad de una aldea, cierto dominio señorial -las famosas inmunidades - o el control de los espacios baldíos de disfrute comunitario, además de profiliaciones y donaciones hechas por pequeños propietarios -eso es lo que parece que son- favorables a monasterios y magnates.

A medida que se acerca el fin del siglo este tipo de documentación aumenta, desembocando en el siglo XI con unas características que se pueden señalar ya como feudales. A las antes mencionadas formas de acceder a la propiedad o el dominio de bienes o de personas se unen magnates que se benefician de la administración de justicia para acumular nuevas propiedades.

En resumen, a pesar de que ciertas instituciones feudo-vasalláticas no se reflejen en la documentación, ésta muestra una sociedad feudalizada, desde la segunda mitad del siglo $x$, en la que los diversos componentes de orden económico, social y político están comenzando a articularse más a través de relaciones privadas que públicas. Las causas fundamentales que lo provocan son la pérdida de soberanía real y las vinculaciones entre señores y campesinos. 